\title{
HIV-positive MSM's knowledge of HPV and anal cancer self-sampling: A scoping review
}

M.K.L. Poon MSW PhD, ${ }^{*}$ J.P.H. Wong RN PhD, ${ }^{\dagger}$ A.T.W. Li MD, ${ }^{\ddagger \S ~ M . ~ M a n u b a ~ B S c ~ B S c N(C), ~}{ }^{\dagger}$ A. Bisignano $B A(C), \S$ M. Owino $M A(C))^{\S}$, and M. Vahabi RN $\mathrm{PhD}^{\dagger}$

\begin{abstract}
Human papillomavirus (HPv) infection is the cause of anal squamous cell cancer (ASCC) in $80 \%$ of cases. Available research has also shown high prevalence of anal HPv infection among men who have sex with men (MSM). However, HPV vaccination is low among MSM in Canada. In light of this information, we conducted a scoping review with the aim of exploring (1) the knowledge of HPV and anal cancer among HIV-positive MSM and (2) the acceptability of HPV and anal cancer self-sampling in this population. In conducting the review, we searched five electronic databases for peer-reviewed articles and abstracts published in English, between 2007 and 2017. A total of 803 articles were retrieved; after accounting for duplicates $(n=40)$ and unmet criteria $(n=754)$, a total of 794 articles were excluded. A final total of nine articles were used in this review. Results of this review show that HIv-positive msm have limited knowledge regarding the risks of anal cancer associated with HIV and HPV coinfection. Furthermore, there is limited research on HPV and anal cancer self-sampling in this population. However, the review of available studies suggested that HIV-positive MSM were open to anal cancer self-sampling. It also identified potential barriers to self-sampling. In conclusion, we provide suggestions and future directions for policy-makers and educators to develop inclusive and accessible strategies to reach HIV-positive MSM regarding anal cancer education and self-screening.
\end{abstract}

Key Words MSM, HIV, HPV, anal cancer, self-screening

Curr Oncol. 2018 Feb;25(1):e83-e89

www.current-oncology.com

\section{INTRODUCTION}

Human papillomavirus (HPV) infection is the cause of anal squamous cell cancer (ASCC) in $80 \%$ of cases ${ }^{1}$. Studies in countries around the world show that the prevalence of anal HPV infection is high among men who have sex with men (MSM): for example, $85 \%$ of HIV-positive MSM and $59 \%$ of HIV-negative MSM in Bangkok ${ }^{2}$; $95 \%$ of HIV-positive MSM in $\mathrm{Mumbai}^{3}$; $93 \%$ of $\mathrm{HIV}$-positive men and $64 \%$ of HIVnegative men in Lima ${ }^{4}$; $83 \%$ of HIV-positive MSM and $63 \%$ of HIV-negative MSM in three cities in China ${ }^{5}$; and $65 \%$ of HIVpositive MSM and $45 \%$ of HIV-negative MSM in Amsterdam ${ }^{6}$. Systematic reviews and pooled prevalence also show that anal HPV infection is consistently higher among HIV-positive MSM than HIV-negative MSM. Further, high-risk HPV-16 was detected in $35 \%$ of HIV-positive men and $13 \%$ of HIV-negative men, which may also explain the higher rate of anal cancer incidence among HIV-positive MSM (46 per 100,000 per year) than HIV-negative men (5 per 100,000 per year) ${ }^{7}$.

Despite solid evidence of the high prevalence of anal cancer among HIV-positive MSM, the lack of large-scale rigorous clinical research on the efficacy of HPV and anal cancer screening has created debates ${ }^{8,9}$ and impeded the development of national standards or guidelines on HPV or anal cancer screening of HIV-positive MSM ${ }^{10}$. Further, the attention of policy-makers has largely been given to school-based HPV vaccination programs as the solution to build population immunity against HPV. However, the impact of HPV vaccination is far from immediate and its impact on protecting HIV-positive MSM from related cancers remains to be seen. Studies in Canada and elsewhere show that HPV vaccination rates among MSM (outside of school-based programs) are low, ranging from $7 \%$ to $21 \%{ }^{11-12}$. Other studies also indicate that MSM also have low knowledge about HPV-related cancers $^{14}$. A recent systematic review of 16 studies shows that the majority of MSM sampled had a poor understanding of HPV and its causal role in cancer affecting them. In addition, the majority of participants did not perceive themselves as being at risk of HPV or related diseases ${ }^{15}$.

Currently, a number of methods are used to screen HPV and HPV-related cancer: (1) visual inspection and removal of anogenital warts; (2) anal cytology examinations (anal Pap smear) to identify HPV types and/or to detect early signs of cancer precursors or dysplasia; (3) digital anorectal examinations (DARE) to identify abnormal masses; and (4) high-resolution anoscopy (HRA) to detect high-grade 
lesions ${ }^{10}$. All these methods have specific merits and weaknesses. Visual inspection does not provide critical information about the HPV strains and related risk for anal cancer. Digital anorectal examinations may detect advanced anal cancer but not pre-cancerous changes; and DARE is not acceptable to all patients ${ }^{16}$. Abnormal anal cytology is very common (67\%) among HIV-positive MSM and requires confirmation with HRA, which can only be performed by anoscopists ${ }^{8}$. Further, all these screening methods are performed in clinical settings, which are not accessible to all HIV-positive MSM due to barriers such as hours of operation, travel distance, and lack of access to primary care providers ${ }^{17}$.

\section{METHODS}

This scoping review was guided by the framework developed by Arksey and O'Malley ${ }^{18}$. Based on discussions in community think-tanks, our team decided on two research questions: (1) What has been reported on the knowledge of HPV and anal cancer among HIV-positive MSM? (2) What has been reported about the acceptability of HPV and anal cancer self-sampling among HIV-positive MSM? We chose to focus on HIV-positive MSM because a systematic review has been conducted of MSM in general ${ }^{15}$. Further, HIV-positive MSM are at increased risk of anal cancer compared with HIV-negative MSM.

The search was limited to peer-reviewed articles published in the last 10 years (2007-2017). We initially set the limit to include only research in Canada. However, our search yielded only one article. We therefore expanded our search to articles published in Western countries such as the United States, Australia, and in Europe, which share similar social, economic, and political contexts as Canada. Due to the scarcity of studies in these two topics, we included studies that contained a subsample of HIV-positive MSM.

To identify relevant articles, we searched the following major databases: CINAHL, Google Scholar, Medline, Nursing and Allied Health, and Web of Science. The search terms included: knowledge, HIV-positive, HIV-infected, MSM, gay men, bisexual men, HPV, human papilloma virus, human papillomavirus, anal cancer, acceptability, attitudes, willingness, self-collection, self-sampling, and self-screening. Upon the removal of all duplicated articles, we reviewed the titles and abstracts of the remaining items to determine whether they met the inclusion criteria. Full articles were reviewed when the abstract provided insufficient information to determine inclusion or exclusion. Dissertations/thesis abstracts were excluded due to resource constraints. Articles that met the inclusion criteria were reviewed in detail, and relevant results were extracted for analysis and synthesis (see Figure 1). Significant study information based on study authors, year of publication, study purpose, study approach, study population, and study country was organized using a standard data extraction table (see Table I).

\section{RESULTS}

A total of nine articles met the inclusion criteria: six articles pertained to knowledge of HPV and anal cancer among

\begin{tabular}{|c|c|c|}
\hline Databases & $\begin{array}{l}\text { Knowledge of } \\
\text { HPV/Anal. Ca }\end{array}$ & $\begin{array}{l}\text { Acceptability - } \\
\text { Self-Sampling }\end{array}$ \\
\hline PubMed & 10 & 23 \\
\hline CINAHL & 8 & 4 \\
\hline OVID/Medline & 16 & 3 \\
\hline ProQuest & 89 & 13 \\
\hline Google Scholar & 560 & 77 \\
\hline \multicolumn{3}{|c|}{$\downarrow$} \\
\hline \multicolumn{3}{|c|}{$\begin{array}{l}\text { Total \# of abstracts ret rieved from } \\
\text { databases }(N=803) \\
\text { Knowledge }(n=683) \\
\text { Acceptability of SS }(n=120)\end{array}$} \\
\hline \multirow{2}{*}{\multicolumn{3}{|c|}{$\frac{\downarrow}{\text { Total \# of abstracts excluded ( } N=794)}$}} \\
\hline & & \\
\hline \multicolumn{2}{|r|}{ Knowledge } & Acceptability \\
\hline Duplication & 35 & 5 \\
\hline $\begin{array}{l}\text { Inclusion } \\
\text { criteria not met }\end{array}$ & 642 & 112 \\
\hline \multicolumn{3}{|c|}{$\begin{array}{l}\text { Total \# of it ems reviewed }(\mathbf{N}=9) \\
\text { Knowledge - articles }(n=6) \\
\text { Acceptability of SS - Articles }(n=3)\end{array}$} \\
\hline
\end{tabular}

FIGURE 1 Search processes. HPV = human papillomavirus; SS = self-sampling.

HIV-positive MSM, and the remaining three articles related to acceptability of self-sampling among MSM. Four studies were conducted in the United States ${ }^{19-22}$, three in Austra$\operatorname{lia}^{23-25}$, and the remaining two in Canada ${ }^{26}$ and Serbia ${ }^{27}$, respectively. All articles related to HPV and anal cancer knowledge were quantitative, utilizing self-administered questionnaires for data collection. Two of the three articles related to acceptability of self-sampling among HIv-positive MSM were quantitative and the final study was qualitative, using semi-structured interviews to explore attitudes and barriers towards anal self-examination among HIVpositive MSM. Overall, four of the studies focused solely on HIV-positive MSM; the other five studies consisted of mixed samples of HIV-positive MSM and HIV-negative MSM.

We used a deductive approach, focusing on our scoping review questions, to analyze the results of these nine articles and generated five themes: (1) gaps in knowledge about HPV, anal cancer, and cancer screening; (2) factors associated with knowledge; (3) perceived risk of and susceptibility to HPV anal cancer; (4) acceptability and feasibility of anal cancer self-sampling; and (5) barriers related to self-sampling. 
TABLE I HIV-positive MSM results table

\begin{tabular}{|c|c|c|c|c|}
\hline Reference & Location & Study objectives & Sample/Participants & Study approach \\
\hline \multicolumn{5}{|c|}{ Knowledge of HPV and anal cancer among HIV-positive MSM } \\
\hline Bjekic et al., $2016^{27}$ & Serbia & $\begin{array}{l}\text { This study assessed the level of } \\
\text { knowledge related to HPV, anal cancer, } \\
\text { anal cancer screening, and the HPV } \\
\text { vaccine among MSM. This study also } \\
\text { compared the knowledge level between } \\
\text { HIV-positive and HIV-negative MSM. }\end{array}$ & $\begin{array}{l}142 \text { HIV-positive men who } \\
\text { underwent regular checkups at } \\
\text { the Institute for Infectious and } \\
\text { Tropical Diseases and } 128 \text { HIV- } \\
\text { negative MSM who attended } \\
\text { counselling for STIs at the City } \\
\text { Institute for Skin and Venereal } \\
\text { Diseases }\end{array}$ & $\begin{array}{l}\text { Quantitative: } \\
\text { interviewer- } \\
\text { administered } \\
\text { questionnaire, } \\
\text { cross-sectional study }\end{array}$ \\
\hline Fenkl et al., $2015^{19}$ & United States & $\begin{array}{l}\text { This study examined the effect of } \\
\text { an educational program on level of } \\
\text { knowledge and awareness of anal } \\
\text { cancer screening among HIV-positive } \\
\text { MSM }\end{array}$ & $\begin{array}{l}94 \text { HIV-infected MSM } \\
(\text { mean age }=51.9)\end{array}$ & $\begin{array}{l}\text { Quantitative: } \\
\text { investor-developed } \\
\text { questionnaire }\end{array}$ \\
\hline Gilbert et al., $2011^{20}$ & United States & $\begin{array}{l}\text { This study examined HPV-related } \\
\text { knowledge attitudes, and beliefs among } \\
\text { HIV-positive and HIV-negative men. }\end{array}$ & $\begin{array}{l}188 \text { HIV-positive gay men (mean } \\
\text { age }=51) \text { and } 59 \text { HIV-negative } \\
\text { gay men (mean age }=47 \text { ) }\end{array}$ & $\begin{array}{l}\text { Quantitative: } \\
\text { online survey }\end{array}$ \\
\hline Kahn et al., $2017^{21}$ & United States & $\begin{array}{l}\text { This study evaluated the risk perception } \\
\text { among HIV-positive MSM related to HPV } \\
\text { following HPV vaccination. This study } \\
\text { also identified factors associated with } \\
\text { risk perception. }\end{array}$ & $\begin{array}{l}142 \text { HIV-positive MSM } \\
(\text { mean age }=23 \text { ) }\end{array}$ & $\begin{array}{l}\text { Quantitative: } \\
\text { paper-and-pencil } \\
\text { self-administered } \\
\text { questionnaire }\end{array}$ \\
\hline Ong et al., $2015^{23}$ & Australia & $\begin{array}{l}\text { This study assessed participants' } \\
\text { awareness, knowledge, and risk } \\
\text { perception related to anal cancer } \\
\text { among HIV-positive MSM. }\end{array}$ & $\begin{array}{l}327 \text { HIV-positive MSM } \\
\text { recruited from clinical settings } \\
\text { in Melbourne, Australia, } \\
\text { aged } 35+\end{array}$ & $\begin{array}{l}\text { Quantitative method: } \\
\text { written questionnaire, } \\
\text { cross-sectional study }\end{array}$ \\
\hline Pitts et al., $2007^{24}$ & Australia & $\begin{array}{l}\text { This study evaluated levels of } \\
\text { experience and knowledge concerning } \\
\text { anal dysplasia, anal Pap smear tests, and } \\
\text { HPV among MSM. }\end{array}$ & $\begin{array}{l}384 \text { MSM attending a large } \\
\text { community event in Melbourne, } \\
\text { aged } 16-67 ; 6.4 \% \text { of participants } \\
\text { were HIV-positive }\end{array}$ & $\begin{array}{l}\text { Quantitative method: } \\
\text { short survey, cross- } \\
\text { sectional study }\end{array}$ \\
\hline \multicolumn{5}{|c|}{ Acceptability of HPV self-screening } \\
\hline Gilbert et al., $2011^{26}$ & Canada & $\begin{array}{l}\text { This study evaluated the prevalence } \\
\text { of HPV infection and anal dysplasia } \\
\text { among MSM in Vancouver. This } \\
\text { study also assessed the feasibility of } \\
\text { incorporating SCRS into an existing } \\
\text { venue-based HIV surveillance system } \\
\text { for MSM. }\end{array}$ & $\begin{array}{l}766 \text { MSM (aged > 19, } \\
125 \text { HIV-positive) }\end{array}$ & $\begin{array}{l}\text { Quantitative: } \\
\text { self-administered } \\
\text { questionnaire } \\
\text { Self-sampling tool: } \\
\text { self-collected } \\
\text { rectal swab }\end{array}$ \\
\hline Ong et al., $2014^{25}$ & Australia & $\begin{array}{l}\text { This study explored acceptability and } \\
\text { barriers to anal self-examination (ASE) } \\
\text { as a method of anal cancer screening. }\end{array}$ & $\begin{array}{l}20 \text { HIV-positive MSM } \\
\text { (aged 35-78) }\end{array}$ & $\begin{array}{l}\text { Qualitative: semi- } \\
\text { structured interviews } \\
\text { Self-sampling tool: } \\
\text { no self-sampling } \\
\text { device was assessed } \\
\text { in this study }\end{array}$ \\
\hline Thompson et al., $2015^{22}$ & United States & $\begin{array}{l}\text { This study explored gay and bisexual } \\
\text { men's willingness to self-administer an } \\
\text { anal screening test at home. }\end{array}$ & $\begin{array}{l}\text { Two national, online cross- } \\
\text { sectional surveys were done: } \\
\text { Study I in } 2009 \text { consisted of } \\
306 \text { self-identified gay and } \\
\text { bisexual men (aged 20-59, 17\% } \\
\text { HIV-positive). Study II in 2013 } \\
\text { consisted of } 428 \text { men (aged } \\
\text { 18-26, } 4 \% \text { HIV-positive) }\end{array}$ & $\begin{array}{l}\text { Quantitative: survey, } \\
\text { cross-sectional } \\
\text { Self-sampling tool: } \\
\text { self-collected } \\
\text { rectal swab }\end{array}$ \\
\hline
\end{tabular}

MSM = men who have sex with men; HPV = human papillomavirus; STI = sexually transmitted infection; SCRS = self-collected rectal swabs 


\section{Gaps in knowledge about HPV and anal cancer}

Across all studies, HIV-positive MSM demonstrated an overall limited knowledge related to HPV and anal cancer. A study conducted in Serbia found that only $64.8 \%$ of the 142 HIV-positive MSM participants had heard of HPV; furthermore, only $34.5 \%$ and $19.7 \%$ were aware that HPV causes anal and penile cancer, respectively ${ }^{27}$. Another study conducted in the United States found that, although $71 \%$ of the 59 HIV-positive MSM believed that HIV increases their risk of getting genital warts, $75 \%$ of them had heard of HPV vaccine but only $27 \%$ of them believed that HPV vaccine worked in men ${ }^{20}$.

Regarding knowledge of symptoms of HPV and treatment methods, there were some inconsistent results among different studies. In the Serbian study, only $45.8 \%$ of the participants were aware that HPV infection might be asymptomatic. ${ }^{27}$ However, in a study conducted in the United States, $98 \%$ of the 142 HIV-positive MSM participants were aware that HPV could be asymptomatic. This same study also found that $61 \%$ of the men knew that genital warts might not be resolved permanently after treatment, but only $40 \%$ knew HPV infection could not be cured with antibiotics ${ }^{21}$.

Results were also inconsistent regarding participants' knowledge of HPV associated with anal cancer. In a study based in Australia, over a quarter (28\%) of the 327 HIVpositive MSM participants had never heard of anal cancer; among those who stated that they have heard of anal cancer, $47 \%$ were not aware of the risk factors for anal cancer, and $46 \%$ scored 5 or lower out of 10 in knowledge questions $^{23}$. The study in Serbia reported that only $34.5 \%$ of the participants were aware of the HPV and anal cancer association $^{27}$. In contrast, one American study found that $100 \%$ of the 94 HIV-positive MSM participants correctly identified HPV as a cause of anal cancer. However, only $36 \%$ of participants in the same study knew that HPV causes genital warts ${ }^{19}$. Similarly, the Australian and Serbian studies found that only half of the participants were aware that HPV causes genital warts ${ }^{23,27}$.

\section{Knowledge of HPV and anal cancer screening}

With regard to HPV and anal cancer screening, there seems to be limited awareness of anal Pap smears. In a study conducted in the United States, the majority of the 94 HIV-positive MSM could not correctly answer questions regarding anal Pap smears. For example, most of the men thought that an anal Pap smear is not required if you are HIV-negative and have no history of sexually transmitted infections (sTIs) ${ }^{19}$. In the Serbian study, only $19 \%$ of the 142 HIV-positive MsM participants indicated that they had ever heard of anal Pap smears, and $2.8 \%$ had previously had an anal Pap smear ${ }^{27}$. Another study conducted in Australia also found that only $29.2 \%$ of 24 HIV-positive MSM participants had ever received an anal Pap smear test ${ }^{24}$.

\section{Factors associated with knowledge about HPV and anal cancer}

We identified several factors associated with HIV-positive MSM's knowledge about HPV and anal cancer. Two studies found that participants with a higher education were more knowledgeable on HPV and anal cancer ${ }^{19,24}$. Other important factors associated with higher knowledge about HPV and anal cancer were having a history of sTI or genital warts ${ }^{21}$ and receiving information from health care providers. However, a study in Australia found that receiving tertiary (higher) education was associated with poor knowledge related to anal cancer ${ }^{23}$; this study also found that participants who had lower knowledge about anal cancer tended to be older, speak English at home, and be less likely to perform anal self-examination or consult with health care providers regarding anal cancer ${ }^{23}$.

Only two studies compared HIV-positive MSM's knowledge of HPV and anal cancer with HIV-negative MSM's. They both found that HIV-positive MSM tend to have greater HPVrelated knowledge than HIV-negative $\mathrm{MSM}^{20,27}$. The Serbian study also found that a larger percentage of HIV-positive MSM (34.5\%) had a greater awareness of the link between HPV and anal cancer than HIV-negative MSM $(22.7 \%)^{27}$. However, in the same study, a lower proportion of HIV-positive MSM than HIV-negative MSM knew that HPV does not cause genital herpes $(9.2 \% \text { vs. } 20.3 \%)^{27}$. Furthermore, in the American study that examined how HIV status may influence HPV-related knowledge, attitudes, and beliefs, HIVpositive Msm had a higher perceived risk of being infected with HPV and indicated greater concern for HPV-related illnesses than HIV-negative MSM. However, HIV status was not associated with the belief that HPV increased risk for genital warts and anal cancer. Among HIV-positive MSM, higher perceived severity of HPV-related disease and lower perceived access barriers to health services seemed to be associated with higher acceptability of accessing preventive services such as HPV vaccine ${ }^{20}$.

The results of these studies suggest that more studies, using comprehensive approaches to explore the complex social contexts of health literacy among diverse groups of HIV-positive MSM, are needed to gain a deeper understanding about factors that influence HIV-positive MSM's knowledge about HPV and anal cancer.

Perceived risk of and susceptibility to HPV anal cancer Perceived susceptibility to HPV infection and anal cancer among HIV-positive MSM in this review was generally low. An Australian study found that over half of the HIV-positive MSM participants believed that their risk for anal cancer was 'about the same,' 'lower,' or 'much lower' when compared with an average man who was the same age and HIV-negative. The researchers suggested that these men's perceptions were associated with their low knowledge about anal cancer and never having had an anal examination by health care providers ${ }^{23}$.

HIV-positive MSM appeared to have varying knowledge about factors that increase the risk for HPV and anal cancer. In one American study, none of the $91 \mathrm{HIV}$-positive participants knew that being HIV-positive increased the risk for anal cancer ${ }^{19}$. However, $43.9 \%$ of the HIV-positive MSM in the Serbia-based study ${ }^{27}$ and $77 \%$ in another American study $^{2}$ showed that they were aware of the increased risk of anal cancer related to $\mathrm{HIV}^{20}$. What seemed alarming was that some studies found that many HIV-positive MSM still did not consider a high number of sexual partners (50\%) and failure to use condoms (48\%) as risks for anal cancer ${ }^{27}$ 
and were not aware that being HIV-positive increased their risk for genital warts ${ }^{20}$.

Studies also found that there was an inadequate awareness among HIV-positive MSM that condoms do not completely protect against HPv infection. In one American study, when asked if condoms could prevent the transmission of HPV, only $2 \%$ of the 94 men answered correctly prior to their participation in an anal cancer screening program $^{19}$. Similarly, one study in Australia found that $75 \%$ of participants did not know that condoms do not always prevent HPV transmission ${ }^{23}$. However, participants in another study demonstrated higher levels of knowledge; $70 \%$ of them knew that HPV could be transmitted through skin-to-skin contact, and $65 \%$ knew that condoms do not completely protect against $\mathrm{HPV}^{21}$.

\section{Acceptability and feasibility of anal cancer self-sampling}

In general, self-sampling for HPV and HPV-related diseases was found to be acceptable among MSM. One article reporting on two national online surveys investigating the acceptability of self-collected anal cancer screening tests among MSM indicated self-sampling to be widely acceptable ${ }^{22}$; $90 \%$ of 51 HIV-positive MSM were willing to self-administer an anal cancer screen test in Study I, and $72 \%$ of $18 \mathrm{HIV}$ positive MSM in Study II were willing to self-collect ${ }^{22}$. Factors found to be associated with acceptability included greater knowledge of HPV, greater perceived risk of developing anal cancer, belief that HIV infection increased risk of getting anal cancer, being HIV-positive, having multiple (five or more) sexual partners, having higher education, being older, and being non-Hispanic white when compared with other races/ethnicities ${ }^{22}$. Similarly, a qualitative study in Australia investigating attitudes of HIV-positive MSM $(n=20)$ towards conducting a self-digital anal rectal exam (DARE) to screen for abnormal growths related to anal cancer found that most men were willing to perform a DARE despite discomfort ${ }^{25}$. Both of these studies found that willingness to self-screen was greater if participants believed in the benefits of early detection of HPV and anal cancer ${ }^{22,25}$.

Finally, one Canadian study examined the effectiveness of integrating self-collected rectal swabs to screen for HPV infection in community venues commonly visited by Msm such as bars, bathhouses, and community events. The study consisted of two independent components: (i) a survey; and (ii) a sub-study of self-sampling using an anal swab. Participants were given the option of either providing a self-sample in an on-site facility (not available at all venues), or providing a self-sample at a clinic eight weeks later. A total of 766 Msm took part in this study and $16 \%$ (125) were HIV-positive. Of the 766 Msm participants who completed the survey, only $35 \%$ ( $n=268)$ consented to participate in a sub-study of self-sampling. Reasons for nonparticipation included discomfort with self-sampling, lack of time to participate, lack of appropriate on-site space to do self-sampling, and inaccessibility of follow-up sites. However, the study also showed that acceptability of self-sampling was higher among HIV-positive men: $51 \%$ ( $n=64$ ) of the HIV-positive MSM consented to take part in the sub-study of self-sampling, whereas only $26.6 \%$ ( $n=204)$ of HIV-negative MSM consented.

\section{Barriers to self-sampling}

Several barriers to self-sampling were reported in the two studies on acceptability of self-sampling related to HPV and anal cancer. One of the prominent concerns expressed was fear of not being able to conduct the self-sampling test accurately ${ }^{22,25}$. Participants also expressed preference for a health care provider to collect the specimen for HPV or anal cancer ${ }^{22,25}$. In Study II of the aforementioned American study, 29\% of the 428 Msm participants preferred physician-collected over self-sampling ${ }^{22}$. In the Australian study, participants' preference for physician examination was derived from the fear of "missing something" during a self-administered DARE. Feelings of discomfort related to self-sampling or fear that self-sampling would hurt were also reported ${ }^{25}$.

In regard to anal self-examination, a few participants expressed concerns regarding the sexual connotation associated with finger insertion in the anus. Another barrier was a perceived lack of knowledge. Several participants expressed concerns regarding a lack of knowledge related to proper self-examination techniques and an uncertainty about what to assess for. Other barriers to self-sampling included: fear of finding an abnormality, worries of inadequate physical flexibility to perform the examination, and concerns related to hygiene ${ }^{25}$.

\section{DISCUSSION}

With the advent of the HPV vaccine, there has been more research on the knowledge of HPV and related cancer among MSM $^{15}$. However, research on HIV-positive MSM's knowledge and perceptions of HPV and related cancer remains scant. The results of this scoping review showed that HIV-positive MSM have varied awareness of and knowledge about the risks of anal cancer associated with HIV and HPV co-infection. Many have never heard of HPV; their lack of awareness raises questions about health care providers' role and current practices in communicating information to HIV-positive men about HPV and related cancers. Many have not heard about HPV from their service providers. It is noteworthy that variations in the objectives and sampling methods of the reviewed studies might have contributed to the different results about different groups' knowledge, making it difficult to produce a comprehensive picture about HPV knowledge among HIV-positive MSM. Coordinated efforts and comprehensive approaches to explore the complex social contexts of health literacy among diverse groups of HIV-positive MSM are needed.

Given the strong history of activism among MSM communities to innovate and achieve policy and practice change during the early days of the AIDs epidemic ${ }^{28}$, the current low health literacy on HPV and anal cancer among MSM can be interpreted as a failure in public health and health system response. Despite the high rates of anal and other HPV-related cancers among HIV-positive $\mathrm{MSM}^{7}$, and MSM in general, the lack of community-engaged prevention campaigns, the lack of HPV and anal cancer screening guidelines, and the lack of coordinated responses among public health, primary care, HIV/AIDs services, and cancer care create barriers and perpetuate MSM health disparities that are not only socially unjust but also preventable. 
Currently, there is insufficient research on HPV and anal cancer self-sampling to warrant any meaningful recommendations. Results of the three studies on the acceptability of anal cancer self-screening indicate that HIV-positive MSM were open to self-sampling and selfexamination. However, many participants also expressed fears of doing the self-sample incorrectly, concerns of self-sampling devices being inaccurate, and worries of not being able to do a proper self-examination. Furthermore, in the community venue-based study in Canada, only $35 \%$ of the 766 MsM participants consented to take part in the self-sampling sub-study. The high non-participation rates indicate that any effort to engage MSM in self-sampling must be guided by critical health promotion and health equity principles ${ }^{29}$, including comprehensive awareness and education efforts that provide accurate and accessible information, messages that promote self-efficacy, engagement strategies that promote collective empowerment and collective self-determination in MSM communities to address HIV, HPV, and HPV-related cancer syndemics.

To date, there has not been any large randomized trial to evaluate whether anal cancer screening is beneficial to survival rates. Further, the lack of comprehensive research programs to examine the synergistic epidemics of HPV and HPV-related cancers in Canada and elsewhere reinforces these hidden epidemics and justifies non-action among policy-makers and health system decision-makers, as reflected in the lack of national guidelines on anal HPV and cancer screening in Canada and worldwide ${ }^{30}$. The current lack of community-engaged research and the exclusion of qualitative methodologies produce partial knowledge that does not reveal the contextual factors and social conditions that (1) shape HIV-positive MSM's knowledge, perceptions, and health practices; and (2) impede the effective public health and health systems responses.

Some of the current debates in anal cancer screening in comparison with cervical cancer screening include the limited target groups (e.g., MSM, HIV-positive men), mixed evidence and varying clinical speculations about the effectiveness of screening methods, and the lack of data to assess of the long-term effects of screening ${ }^{31}$. Further, there is insufficient evidence on the progression of high-grade squamous intraepithelial lesions (HSIL) to invasive cancer when compared with cervical cancer ${ }^{32}$. However, given the disproportionately high rates of anal cancer among HIV-positive MSM, and MSM in general, regular screening for HPV and anal cancer is of critical importance to reduce health disparity in this population despite current debates of screening efficacy ${ }^{33}$. Based on lessons learned during the early days of the AIDS epidemic, it is time to break the silence about the HIV, HPV, and HPV-related syndemics and mobilize HIV-positive Msm and communities, health service providers, policy-makers, and researchers to address the current health disparities.

\section{CONFLICT OF INTEREST DISCLOSURES}

We have read and understood Current Oncology's policy on disclosing conflicts of interest, and we declare that we have none.

\section{AUTHOR AFFILIATIONS}

*School of Social Work, York University, Toronto, ON; ${ }^{\dagger}$ Daphne Cockwell School of Nursing, Ryerson University, Toronto, ON;
${ }^{\ddagger}$ Regent Park Community Health Centre, Toronto, ON; ${ }^{\S}$ Committee for Accessible AIDS Treatment, Toronto, ON.

\section{REFERENCES}

1. Schim van der Loeff MF, Mooij SH, Richel O, de Vries HJ, Prins JM. HPV and anal cancer in HIV-infected individuals: a review. Curr HIV/AIDS Rep 2014;11(3):250-62.

2. Supindham T, Chariyalertsak S, Utaipat U, et al. High prevalence and genotype diversity of anal HPv infection among MSM in Northern Thailand. PLOS One 2015;10(5):e0124499.

3. Hernandez AL, Karthik R, Sivasubramanian M, et al. Prevalence of anal HPV infection among HIV-positive men who have sex with men in India. J Acquir Immune Defic Syndr 2016;71(4):437-43.

4. Blas MM, Brown B, Menacho L, Alva IE, Silva-Santisteban A, Carcamo C. HPv prevalence in multiple anatomical sites among men who have sex with men in Peru. PLOS One 2015;10(10):e0139524.

5. Li X, Li M, Yang Y, et al. Anal HPv/HIV co-infection among men who have sex with men: a cross-sectional survey from three cities in China. Sci Rep 2016;6:21368.

6. van Aar F, Mooij SH, van der Sande, et al. Anal and penile high-risk human papillomavirus prevalence in HIV-negative and HIV-infected MSM. AIDS 2013;27(18):2921.

7. Machalek DA, Poynten M, Jin F, et al. Anal human papillomavirus infection and associated neoplastic lesions in men who have sex with men: a systematic review and meta-analysis. Lancet Oncol 2012;13(5):487-500.

8. Salit IE. Screening for anal cancer. Cancer Cytopathol 2015;123(11):631-2.

9. Wendling P. Routine anal Pap smear testing gains ground. Int Med News 2008;41(3):23.

10. Leeds IL, Fang SH. Anal cancer and intraepithelial neoplasia screening: a review. World J Gastrointest Surg 2016;8(1):41-51.

11. Cummings T, Kasting ML, Rosenberger JG, Rosenthal SL, Zimet GD, Stupiansky NW. Catching up or missing out? Human papillomavirus vaccine acceptability among 18- to 26 -year-old men who have sex with men in a US national sample. Sex Transm Dis 2015;42(1):601-6.

12. Moores A, Phillips JC, O’Bryne P, MacPherson P. Anal cancer screening knowledge, attitudes, and experiences among men who have sex with men in Ottawa, Ontario. Can J Hum Sex 2015;24(3):228-36.

13. Gerend MA, Madkins K, Phillips G, Mustanski B. Predictors of human papillomavirus vaccination among young men who have sex with men. Sex Transm Dis 2016;43(3):185-91.

14. Colón-López V, Ortiz AP, Del Toro-Mejías LM, García H, Clatts MC, Palefsky J. Awareness and knowledge of human papillomavirus (HPV) infection among high-risk men of Hispanic origin attending a sexually transmitted infection (STI) clinic. BMC Infect Dis 2012;12:346.

15. Nadarzynski T, Smith H, Richardson, D, Jones CJ, Llewellyn CD. Human papillomavirus and vaccine-related perceptions among men who have sex with men: a systematic review. Sex Transm Infect 2014;90 (7):515-23.

16. Read TRH, Vodstrcil L, Grulich AE, et al. Acceptability of digital anal cancer screening examinations in HIV-positive homosexual men. HIV Med 2013;14(8):491-6.

17. Kendall CE, Taljaard M, Younger J, Hogg W, Glazier RH, Manuel DG. A population-based study comparing patterns of care delivery on the quality of care for persons living with HIV in Ontario. BMJ open 2015;5(5):e007428.

18. Arksey H, O'Malley L. Scoping studies: towards a methodological framework. Int J Soc Res Methodol 2005; 8(1):19-32.

19. Fenkl EA, Schochet E, Jones SG, da Costa, BR. Evaluation of an HPV/anal cancer screening awareness program for 
HIV-infected men who have sex with men. JAssoc Nurses AIDS Care 2015;26 (4):492-7.

20. Gilbert PA, Brewer NT, Reiter PL. Association of human papillomavirus-related knowledge, attitudes, and beliefs with HIV status: a national study of gay men. JLow Genit Tract Dis 2011;15(2):83-8.

21. Kahn J, Lee J, Belzer M, Palefsky J. HIV-infected young men demonstrate appropriate risk perceptions and beliefs about safer sexual behaviors after human papillomavirus vaccination. AIDS Behav 2017;1-9.

22. Thompson JA, Reiter PL, McRee AL, Moss JL, Brewer NT. Gay and bisexual men's willingness to use a self-collected anal cancer screening test. JLow Genit Tract Dis 2015;19(4):354-61.

23. Ong JJ, Chen M, Grulich A, et al. Exposing the gaps in awareness, knowledge and estimation of risk for anal cancer in men who have sex with men living with HIv: a cross-sectional survey in Australia. J Int AIDS Soc 2015;18(1):1-7.

24. Pitts MK, Fox C, Willis J, Anderson J. What do gay men know about human papillomavirus? Australian gay men's knowledge and experience of anal cancer screening and human papillomavirus. Sex Transm Dis 2007;34(3):170-3.

25. Ong JJ, Temple-Smith M, Chen M, Walker S, Grulich A, Fairley CK. Exploring anal self-examination as a means of screening for anal cancer in HIV positive men who have sex with men: a qualitative study. BMC Public Health 2014;14:1-7.

26. Gilbert M, Kwag M, Mei W, et al. Feasibility of incorporating self-collected rectal swabs into a community venue-based survey to measure the prevalence of HPV infection in men who have sex with men. Sex Transm Dis 2011;38(10):964-9.

27. Bjekic M, Sipetic-Grujicic S, Dunic I, Salemovic D, Vlajinac H. Human papillomavirus and anal carcinoma knowledge in men who have sex with men in Belgrade, Serbia. IntJDermatol 2016;55(10):1082-7.

29. Laverack G. Health promotion practice: building empowered communities. Open University Press; 2007.

30. Wells JS, Holstad MM, Thomas T, Bruner DW. An integrative review of guidelines for anal cancer screening in HIv-infected persons. AIDS Patient Care STDs 2014;28(7):35-357.

31. Darragh TM, Winkler B. Anal cancer and cervical cancer screening: key differences. Cancer Cytopathol 2011;119(1):5-19.

32. Gautier M, Brochard C, Lion A, et al. High-grade anal intraepithelial neoplasia: progression to invasive cancer is not a certainty. Dig Liver Dis 2016;48(7):806-11.

33. Medford RJ, Salit IE. Anal cancer and intraepithelial neoplasia: epidemiology, screening and prevention of a sexually transmitted disease. CMAJ 2015;187(2):111-5. 